\title{
Stability of Metal-Oxide Varistor Characteristics in Exploitation Conditions
}

\author{
B. LONČAR ${ }^{a, *}$, M. VujisiĆ ${ }^{b}$, K. StankoviĆc And P. OsmokroviĆc ${ }^{b}$ \\ ${ }^{a}$ Faculty of Technology and Metallurgy, University of Belgrade, Karnegijeva 4, 11120 Belgrade, Serbia \\ ${ }^{b}$ Faculty of Electrical Engineering, University of Belgrade \\ Bulevar Kralja Aleksandra 73, 11120 Belgrade, Serbia \\ ${ }^{c}$ Institute of Nuclear Sciences "Vinča", P.O. Box 522, 11001 Belgrade, Serbia
}

(Received May 14, 2009)

\begin{abstract}
Wide-spread use of metal-oxide varistors for non-linearity over-voltage protection results in a variety of possible working conditions. It is therefore essential to have a thorough insight into their reliability in various exploitation environments. The influences of temperature variation, aging and radiation exposure on metal-oxide varistors characteristics were investigated in this paper. Stable and effective over-voltage protection over a wide temperature range is always a desirable property, one which significantly contributes to overall system reliability. Behaviour of metal-oxide varistors in the temperature range from $-50{ }^{\circ} \mathrm{C}$ to $150{ }^{\circ} \mathrm{C}$ was investigated. Aging caused by exploitation was investigated by applying 1000 consecutive double exponential over-voltage pulses to the varistors. Resistance of metal-oxide varistors to the radiation is of special interest in nuclear, military, and space technology. Radiation effects of californium-252 combined neutron/gamma radiation were examined. Voltage-current characteristics, voltage-resistance characteristics and the value of breakdown voltage were used to characterize metal-oxide varistors operation. Non-linearity coefficient, defined from the voltage-current curve, was also used as a parameter. Results are presented with the accompanying theoretical interpretations of the observed changes in metal-oxide varistors behaviour.
\end{abstract}

PACS numbers: $85.85 .+\mathrm{j}$

\section{Introduction}

Varistors are voltage-dependent non-linearity devices with a near-symmetrical characteristic. They can be used for over-voltage protection in the voltage range from about $10 \mathrm{~V}$ to several thousands volts. Of late, metaloxide varistors (MOVs) are mostly used, owing to the good protective properties. A metal-oxide varistor is composed of zinc-oxide $\mathrm{ZnO}$ as a basic material, and additives, primarily bismuth-oxide $\mathrm{Bi}_{12} \mathrm{O}_{3}$, manganeseoxide $\mathrm{MnO}_{2}$ and antimony-oxide $\mathrm{Sb}_{2} \mathrm{O}_{3}$. A varistor is produced via sintering of the zinc-oxide powder with small quantities of the mentioned additives [1,2]. In spite of the fact that they have been used for a long time, there is no uniform description of the principles of varistor operation. The most plausible explanation is based on the formation of a potential barrier in the surface layer of zinc-oxide grains, where $\mathrm{Zn}$ and $\mathrm{O}$-vacancies act as acceptors and donors [3].

An important parameter of every metal-oxide varistor is its breakdown voltage. It is strongly dependent on the concentrations of carriers in $\mathrm{ZnO}$ grains, i.e. on the con-

\footnotetext{
* corresponding author; e-mail: bloncar@tmf.bg.ac.rs
}

centration of electrons in the case of $N$-type zinc-oxide. Breakdown in a varistor, which occurs at the boundary between adjacent semiconductor grains of $\mathrm{ZnO}$, can be represented as a sequence of breakdowns of "elementary" varistors connected in series or in parallel. Varistor breakdown voltage equals the sum of "elementary" varistor breakdown voltages and can be calculated as

$$
U_{p}=\left(\frac{d}{v}-1\right) u_{p}
$$

where $d$ is varistor thickness, $v$ is $\mathrm{ZnO}$ grain size, $U_{p}$ is varistor breakdown voltage, and $u_{p}$ is "elementary" varistor breakdown voltage.

In the previous investigations there was tested the influence of ionizing radiation, temperature, and aging on the following components for over-voltage protection: over-voltage diodes [4], gas-filled surge arresters [5-7] and polycarbonate capacitors [8]. The aim of this paper is to investigate the influence of radiation exposure, temperature variation, and aging on MOV characteristics.

\section{The experiment}

Commercially available MOVs, with $250 \mathrm{~V}$ nominal breakdown voltage and maximum pulse current of $2500 \mathrm{~A}$ were used for the experiments. All varistors were produced by a single manufacturer, with identical nominal 
characteristics, which resulted in low statistical dispersion of the obtained results. Each series of measurements has been performed on a sample consisting of 50 varistors. Varistor characteristics presented in the paper are based on sample mean values.

Experiments were conducted using high-voltage measuring equipment, consisting of a current source with a $3000 \mathrm{~V}$ maximum output voltage, a digital oscilloscope, a dc high voltage power supply and a personal computer. The measuring methodology is based on the computer controlled high quality instrumentation and statistical organization of the experiment. This approach assures high accuracy, reliability and repeatability of measurements. All source functions and internal communication between voltage and current sources were generated using a $\mathrm{D} / \mathrm{A}$ converter. Other instruments were computer controlled via the HP-IB protocol.

The influence of different exploitation conditions on the following characteristics of MOVs was examined: (1) voltage-current characteristic, (2) voltageresistance characteristic, (3) non-linearity coefficient $\alpha=$ $\log \left(I_{2} / I_{1}\right) / \log \left(U_{2} / U_{1}\right)$, and (4) breakdown voltage.

Californium ${ }^{252} \mathrm{Cf}$ isotope was used as $\mathrm{n}+\gamma$ source. Varistors were exposed to three different levels of neutron and gamma fluences ( $\Phi_{\mathrm{n}}$ and $\Phi_{\gamma}$, respectively), given in Table in ascending order. Each fluence level is marked by a number $\left(\mathrm{n}_{\Phi}\right)$ shown in the first column.

TABLE

Values of neutron $\left(\Phi_{\mathrm{n}}\right)$ and gamma $\left(\Phi_{\gamma}\right)$ fluences used for irradiation.

\begin{tabular}{c|c|c}
\hline \hline $\mathrm{n}_{\Phi}$ & $\Phi_{\mathrm{n}}\left[10^{10} \mathrm{~cm}^{-2}\right]$ & $\Phi_{\gamma}\left[10^{13} \mathrm{~cm}^{-2}\right]$ \\
\hline 1 & 3.55 & 8.66 \\
2 & 7.10 & 17.3 \\
3 & 10.66 & 26
\end{tabular}

Temperature dependent investigations were performed in the temperature range from $-50^{\circ} \mathrm{C}$ to $+150^{\circ} \mathrm{C}$. The influence of aging was investigated after 1000 activations by the double exponential current pulses $\left(T_{1}=8 \mu \mathrm{s}\right.$, $T_{2}=20 \mu \mathrm{s}$ ) with the amplitude of $I_{\max }=16 \mathrm{~A}$.

\section{Results and discussion}

In Fig. 1a-d MOVs voltage-current characteristics, voltage-resistance characteristics, breakdown voltage, and non-linearity coefficient are represented versus $n+\gamma$ fluence. According to these plots, MOV exhibits a drop in breakdown voltage due to the increase of the voltagecurrent curve slope, and consequently also a decrease of the non-linearity coefficient. The obtained results are not in full agreement with the expected ones [1]. The experiments have, therefore, been performed several times in strictly controlled conditions, every time with similar results.
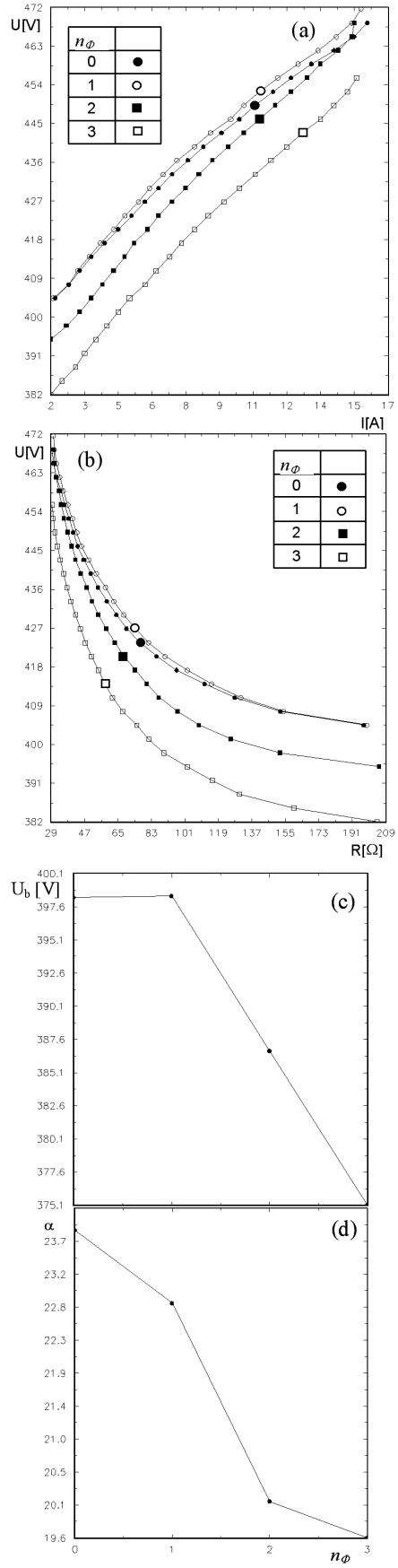

Fig. 1. (a) MOV voltage-current characteristics with $\mathrm{n}+\gamma$ fluence as a parameter, (b) MOV voltageresistance characteristics with $\mathrm{n}+\gamma$ fluence as a parameter, (c) MOV breakdown voltage versus $\mathrm{n}+\gamma$ fluence, (d) MOV non-linearity coefficient versus $n+\gamma$ fluence.

The appearance of dislocations in metal-oxide varistor structure does not change carrier lifetime [1], so no significant influence of $n+\gamma$ radiation on MOV characteristics (voltage-current, voltage-resistance, breakdown voltage, and non-linearity coefficient) is not expected. Nevertheless, experimental results show a significant degradation 


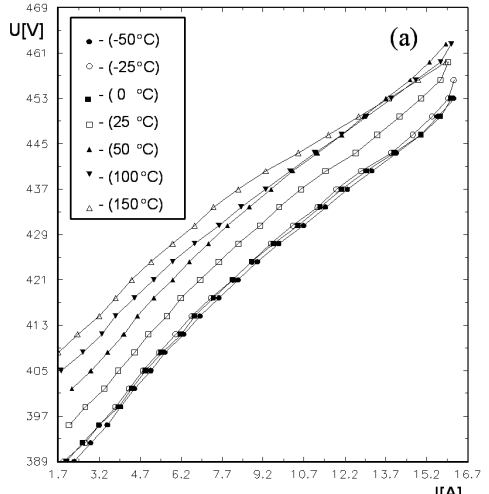

of specific conductivity can account for the changes observed in voltage-current and voltage-resistance curves. On the other hand, decrease of breakdown voltage is caused by the increase of local electric fields. Irreversible changes of electric characteristics of metal-oxide varistors are caused by inelastic interactions with the nuclei of atoms in the material [9]. Since the cross-section for inelastic interaction is much larger for the neutron component than for the corresponding $\gamma$ component, the observed effect is mostly a result of neutron radiation component $[10,11]$.
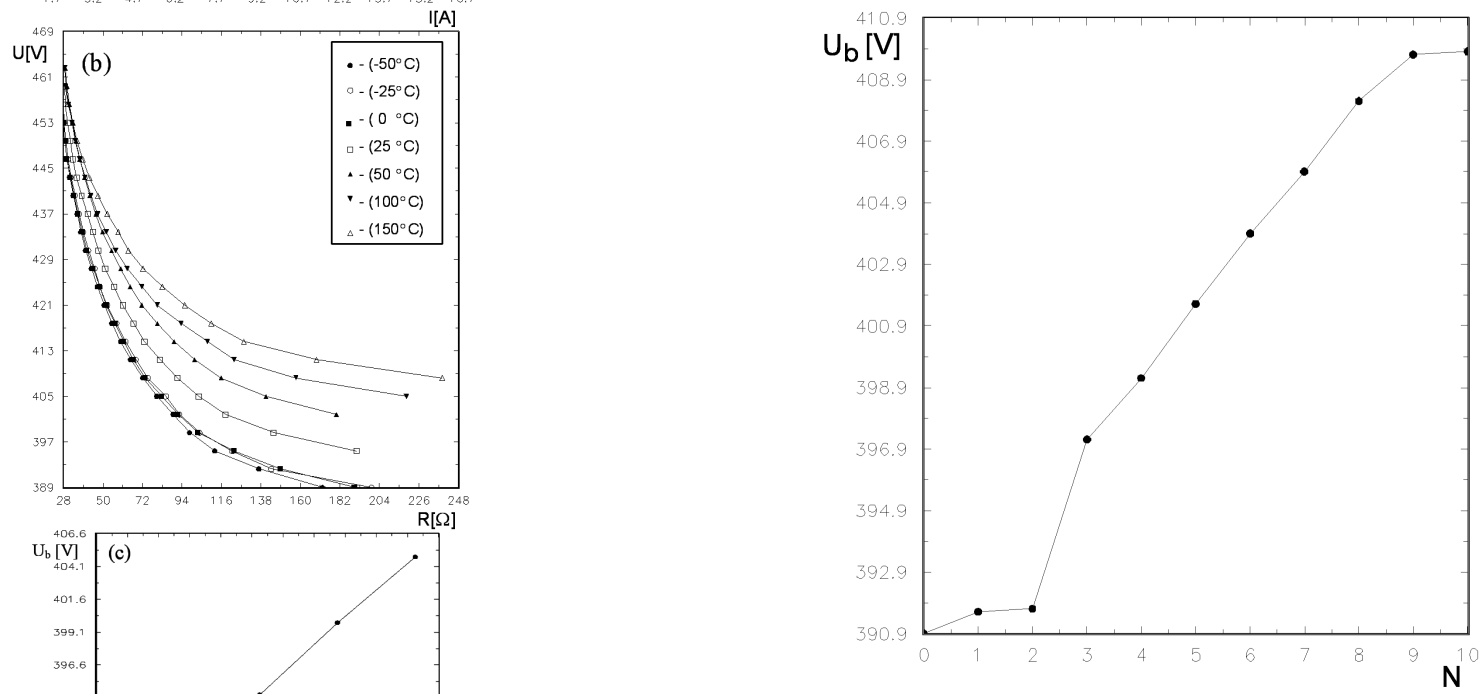

Fig. 3. MOV breakdown voltage versus the number of activation $(\mathrm{n}=$ number of pulses $/ 100)$.

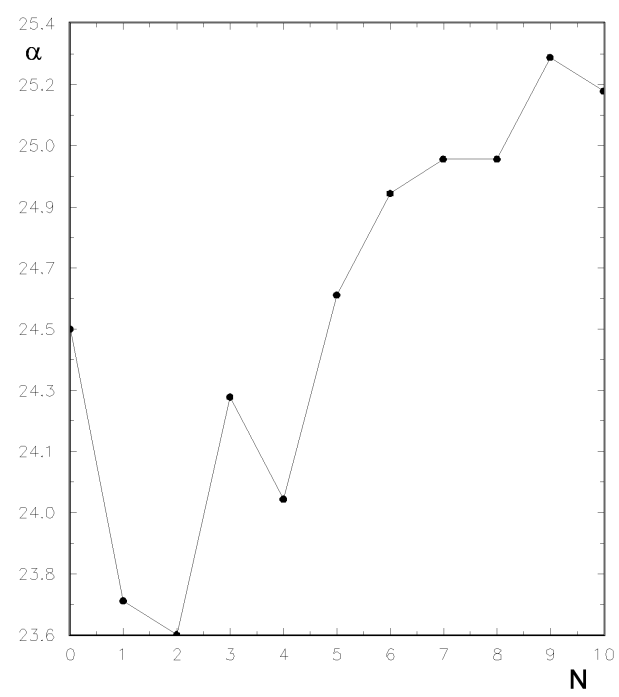

of MOV characteristics. These results may be explained by the capturing of charge carriers at dislocation sites [2], which causes a decrease of free charge carrier concentration. This further leads to a decrease of specific conductivity in metal-oxide varistors and to an increase of local electric field in the proximity of dislocations. Decrease

Fig. 4. MOV non-linearity coefficient $\alpha$ versus the number activation $(\mathrm{n}=$ number of pulses $/ 100)$.

Figure $2 \mathrm{a}-\mathrm{d}$ shows the influence of temperature on voltage-current characteristics, voltage-resistance char- 
acteristics, breakdown voltage, and the non-linearity coefficient $\alpha$ of a MOV. Breakdown voltage of MOVs has shown to be rather resistant to temperature variations in the range from $-50^{\circ} \mathrm{C}$ to $150{ }^{\circ} \mathrm{C}$. Only a change of less than $3 \%$ is noticed. According to the diagram 2d, increasing the temperature of a MOV would improve its protective characteristics. Usually, MOV exhibits much better protection characteristics as compared to over-voltage diodes in the same temperature range [4].

Figures 3 and 4 depict breakdown voltage variation and variation of the non-linearity coefficient dependence on the number of varistor activations. According to these plots, it may be concluded that an increased number of varistor activations results in an increase of the breakdown voltage. We have noticed a slight change in the non-linearity coefficient $\alpha$ (24.5 at the beginning, 25.2 at the end).

These effects can be explained by breaking the MOV chain (on the location of least dissipation). The decrease in MOV effective surface leads to the increase in resistance and breakdown voltage. Larger values of coefficient $\alpha$ (depending on the number of activations) are expected at larger currents. There are two basic causes leading to aging of a MOV: constant varistor current (ac or dc) which is a consequence of the applied voltage, and current pulses caused by over-voltage pulses. This implies that the aging process of a MOV begins immediately when it is connected to the circuit even if no over-voltage pulses occur $[1,2]$. MOVs aging depends on the type of the applied voltage $(\mathrm{ac}$ or $\mathrm{dc}$ ). If a $\mathrm{MOV}$ is connected to dc voltage, aging will be decelerated due to the decrease of breakdown voltage. If ac voltage is applied, varistor aging will become faster due to the increase of breakdown voltage. Another well known property of a MOV is the so-called "memory effect", where the low current discharge increases voltage slightly with exposure to over-voltage. This memory state tends to dissipate over time (weeks to months) [3].

\section{Conclusion}

In this paper, the examination of radiation resistance, temperature stability and aging of MOVs were presented. As has been verified by experimental results, MOVs are devices sensitive to radiation. It was concluded that under $\mathrm{n}+\gamma$ radiation protection characteristics of MOVs degrade considerably. It was also observed that in MOVs appeared noticeable changes in characteristics that are a consequence of aging. On the other hand, MOVs show improvement of their protective characteristics with temperature rise.

\section{Acknowledgments}

The Ministry for Science and Technological Development of the Republic of Serbia supported this work under contract 141046 .

\section{References}

[1] P. Malinaric, IEEE Trans. Electr. Comp. 23, 338 (1985).

[2] D.N. William, IEEE Trans. Ind. Appl. 1A-21, 627 (1985).

[3] C.D. Mahan, L.M. Levinson, H.R. Philipp, J. Appl. Phys. 50, 424 (1979).

[4] M. Vujisic, P. Osmokrovic, K. Stankovic, B. Loncar, J. Optoelectron. Adv. Mater. 9, 3881 (2007).

[5] B. Loncar, P. Osmokrovic, M. Vujisic, A. Vasic, J. Optoelectron. Adv. Mater. 9, 2863 (2007).

[6] B. Loncar, S. Stankovic, A. Vasic, P. Osmokrovic, Nucl. Technol. Rad. Prot. 20, 59 (2005).

[7] K. Stankovic, D. Arandjic, Đ. Lazarevic, P. Osmokrovic, Nucl. Technol. Rad. Prot. 22, 64 (2007).

[8] B. Loncar, P. Osmokrovic, S. Stankovic, R. Sasic, J. Optoelectron. Adv. Mater. 8, 863 (2006).

[9] G. Holmes-Siedle, L. Adams, in: Handbook of Radiation Effects, Oxford University Press, Oxford 2002.

[10] V.S. Vavilov, H.A. Ukhin, in: Radiation Effects in Semiconductors and Semiconductors Devices, Consultants Bureau, New York 1977.

[11] G.C. Messenger, M.S. Ash, in The Effects of Radiation on Electronic Systems, Van Nostrand Reinhold, New York 1992. 